\title{
Syllable Repetition Task
}

National Cancer Institute

\section{Source}

National Cancer Institute. Syllable Repetition Task. NCI Thesaurus. Code C160863.

An 18-item imitation task that assesses a speaker's ability to repeat nonwords. This nonword repetition task was designed specifically for speakers whose incomplete inventories invalidate use of conventional nonword repetition tasks and/or who have speech production patterns that are difficult to transcribe and score. 